\title{
An Assessment of the Knowledge and Practice of Self Breast Examination (BSE) amongst University Students
}

\author{
Adeyemo 0. Florence1, Amiegheme E. Felicia ${ }^{2}$, Adeniran A. Dorcas ${ }^{1}$, \\ Foluke Adebimpe Ade-Aworetan ${ }^{2}$ \\ ${ }^{1}$ Department of Nursing Science, College of Health Sciences, Ladoke Akintola University of Technology, \\ Ogbomoso, Nigeria \\ ${ }^{2}$ Department of Nursing Science, School of Basic Medical Sciences, University of Benin, Benin City, Nigeria \\ Email: *doctoradeyemo@yahoo.com
}

Received 25 January 2016; accepted 13 March 2016; published 16 March 2016

Copyright (C) 2016 by authors and Scientific Research Publishing Inc.

This work is licensed under the Creative Commons Attribution International License (CC BY).

http://creativecommons.org/licenses/by/4.0/

(c) (i) Open Access

\begin{abstract}
Objective: This study sought to assess the knowledge and practice of breast self-examination (BSE) amongst students in the Department of Nursing Science of a tertiary institution in Benin City, Edo State towards self breast examination (SBE). Methods: A descriptive, cross sectional study was conducted in the nursing department of a tertiary institution in Benin City, Edo state. The age range of the study population was between 17-31 years. Convenient sampling technique was used to select 200 female students. The instrument used was a structured questionnaire. The questionnaire was divided into 4 sections: i) Bio-data; ii) knowledge of self breast examination; iii) practice self breast examination; iv) factors affecting SBE. Results: The results of this study indicated that majority of the students were knowledgeable about self breast examination and majority of them practiced self breast examination. The alternate hypothesis which stated that there was a significant difference between factors affecting SBE was retained and the mean values revealed that "forgetfulness" as a factor had the highest mean value. This meant that "forgetfulness" was a potent factor to SBE among the respondents studied. Conclusion: The students in this tertiary institution were aware of self breast examination and they did practice it. Studies like these could enhance the knowledge regarding BSE among nurses and other health professionals.
\end{abstract}

\section{Keywords}

Practice, Knowledge, Self Breast Examination (SBE)

\footnotetext{
*Corresponding author.
}

How to cite this paper: Florence, A.O., Felicia, A.E., Dorcas, A.A. and Ade-Aworetan, F.A. (2016) An Assessment of the Knowledge and Practice of Self Breast Examination (BSE) amongst University Students. Health, 8, 409-415. 


\section{Introduction}

Breast lump usually appears as a firm and painless lump in the breast which may result to cancer later. Breast cancer is the highest cause of mortality in women globally [1]. The incidence of breast cancer is rising more rapidly in population groups that formerly enjoy a low incidence of the disease [2]. Records in Nigeria showed that breast cancer was truly an epidemic amongst women as it was estimated that 211,000 new cases of invasive breast cancer were diagnosed in 2007 and 43,300 patients died of this disease [3]. Breast cancer can be associated with some abnormalities such as inflammatory and malignant conditions such as tumor, which is an abnormal growth, but does not spread outside the breast. There are several types of breast tumor, some are benign and others are cancerous. Examples of the benign tumor are fibro-adenoma, breast cysts and benign mammary dysphasia. Fibro-adenoma is more common among adolescents and early adult which is a fibrocystic disease associated with tiny fluid filled sacs surrounded by connective tissue fibrosis. Fibrocystic changes can cause breast swelling and pains sometimes there is a clear slightly cloudy nipple discharge [4]. The most critical and deadly is breast cancer. It can also be found in men but very rare being of ration 1:100 compared to women [1]. It also tends to occur in hypogonaide males, and those with chromosomal abnormalities. Breast cancer is presently the most common in women in Nigeria and the incidence seems to be on the increase [5]. In 2008, it was estimated that the prevalence of breast cancer in women aged 15 years and over in Sub-Saharan Africa was 23.5 per 100,000 women [6]. It was documented that the incidence of breast cancer in Nigeria had risen significantly with incidence between the year 2009-2010 at 54.3 per 100,000 thereby representing a hundred percent increase in the last decade [7]. There are lots of epidemiological variation in the occurrence of breast cancer in the developed and developing countries [8]. Every woman is at risk of breast cancer [9]. The exact cause of breast cancer is not yet known, but certain risk factors are associated with the disease, which include smoking, and the use of hormonal pills which can be controlled. Others causes include age and family history which can also be controlled.

The promotion of self breast examination (SBE) is very important and it should be encouraged as part of general body care. About $90 \%$ of breast tumors are initially known by women themselves [10]. A high percentage of breast carcinoma is palpable and can be detected early as at a size of about $1 \mathrm{~cm}$. The high mortality rate of breast cancer can be reduced through early detection strategies which include mammography and physical examination (self breast examination) [11]. It is sad to know that most female physicians and nurses (65\% and 70\% respectively) believe that self breast examination is unnecessary; therefore there is need to evaluate self breast cancer awareness and knowledge and practice among the nursing students who are going to be part of the future health personnel [12]. It is also noticed that many of the nursing students only discover that they have lumps during medical examination conducted by the institution during admission and these lumps are excised. This study is aimed at assessing the knowledge and practice of SBE amongst university students in Benin City, Edo State.

\subsection{Objectives}

The objectives of this study are as follows:

1) To assess the knowledge of self breast examination amongst university students of the University of Benin.

2) To find out the practice of the students towards self breast examination.

\subsection{Research Question}

1) What is the knowledge of the students from the University of Benin, Benin City, Edo State about SBE?

2) Do the students practice SBE?

\subsection{Hypothesis}

There are no significant differences between factors affecting SBE practice amongst university students.

\section{Research Methodology}

Research Design: Research design of this study is descriptive.

Setting: The research study was carried out in the nursing department of the University of Benin, Edo State. 
Target Population: The populations of this study are nursing students between age 17 - 31 years. The total population in the department is 400 .

Sampling Technique: Convenient sampling technique was used to select 200 female students unevenly across all the levels as shown in Table 1.

\section{Instrument for Data Collection}

After thorough review of literature a structured questionnaire was developed by the researcher. The questionnaire was divided into 4 sections: sections A (bio data), B (questions on knowledge of self-breast examination), $\mathrm{C}$ (questions on the practice of self-breast examination) and D (questions on misconception of nursing students towards self breast examination).

Validity of Instrument: The questionnaires were validated by the experts in that area.

Reliability: Test retest method was used for the reliability of the instrument. The result was 0.8 .

Method of Data Analysis: Analysis of the data was done using frequency table, pie and bar charts.

Ethical Consideration: Permission to conduct the study was obtained from individual students, and only those who gave their consent were used for the study. The relevance of the study was explained to the respondents before the distribution of the questionnaires.

\section{Results}

\subsection{Research Question One}

What is the knowledge of nursing students from a tertiary institution in Benin City, Edo State towards SBE?

Frequency and percentages were employed to answer this research question and presented in Table 2 and Table 3.

Table 1. Showing distribution of female students according to their year of study.

\begin{tabular}{ccc}
\hline $\mathbf{s} / \mathbf{n}$ & Class level & No \\
\hline 1 & Year 1 & 30 \\
2 & Year 2 & 32 \\
3 & Year 3 & 70 \\
4 & Year 4 & 22 \\
5 & Year 5 & 46 \\
\end{tabular}

Table 2. Frequency of knowledge of nursing students towards SBE.

\begin{tabular}{ccc}
\hline Knowledge of SBE & Number of respondents & Percentage (\%) \\
\hline Knowledgeable of SBE & 187 & $93.5 \%$ \\
Not knowledgeable & 13 & $6.5 \%$ \\
Total & $\mathbf{2 0 0}$ & $\mathbf{1 0 0 \%}$ \\
\hline
\end{tabular}

Table 3. Showing when last the respondents examine their breast.

\begin{tabular}{|c|c|c|}
\hline When last did you examine your breast & Frequency & Percentage (\%) \\
\hline Less than one month & 67 & $33.5 \%$ \\
\hline Two to six months ago & 58 & $29 \%$ \\
\hline When I feel pain & 32 & $16 \%$ \\
\hline At convenience & 31 & $15.5 \%$ \\
\hline Others & 12 & $6 \%$ \\
\hline Total & 200 & $100 \%$ \\
\hline
\end{tabular}


As presented in Table 2 majority of the respondents (93.5 percent) are knowledgeable about SBE while only 6.5 per cent $(\mathrm{N}=13)$ are not knowledgeable about SBE. This could be explained by their disposition as nursing students; the little number in the sample that is not knowledgeable may be the year one students.

As presented in table 3, 33.5 per cent of the respondents examined their breast at least once in less than month before the survey, $29 \% 2$ - 6 months ago, $16 \%$ when there is pain, $15.5 \%$ at convenience.

\subsection{Research Question Two}

Do nursing students from a tertiary institution in Benin City, Edo State practice SBE?

Simple percentages and frequency was employed to answer this research question and is presented in Table 4 through 6 and Figure 1.

Table 4 shows that 75 per cent of the respondents examined their breast regularly while 25 per cent did not.

As presented in Table 5, majority of the respondents 84.5 percent $(\mathrm{N}=169)$ freely performed SBE while only 15.5 percent $(\mathrm{N}=31)$ did not see any reason to do so.

Table 6 shows that the majority of the respondents carried out self breast examination in front of mirror 102 (51\%), 41(20.5\%) when taking a shower, 26(13\%) Hospital, while 31 (15.5\%) did not see any reason at all to examine their breast.

Bar Chart Showing Distribution According to Time of the Month Respondents Examine Their Breast

As presented in Figure 1 and Table 4, respondents carried out self breast examination before menstruation, after menstruation, during menstruation and at their convenience. Those who did SBE at their convenience are more 65.0 percent in the sample while only very few 6.5 per cent respondents carried out SBE during menstruation.

\section{Hypothesis One}

There is no significant difference between factors affecting SBE, this hypothesis was tested using one way analysis of variance (ANOVA) at 0.05 level of significance, the result is presented in Table 7.

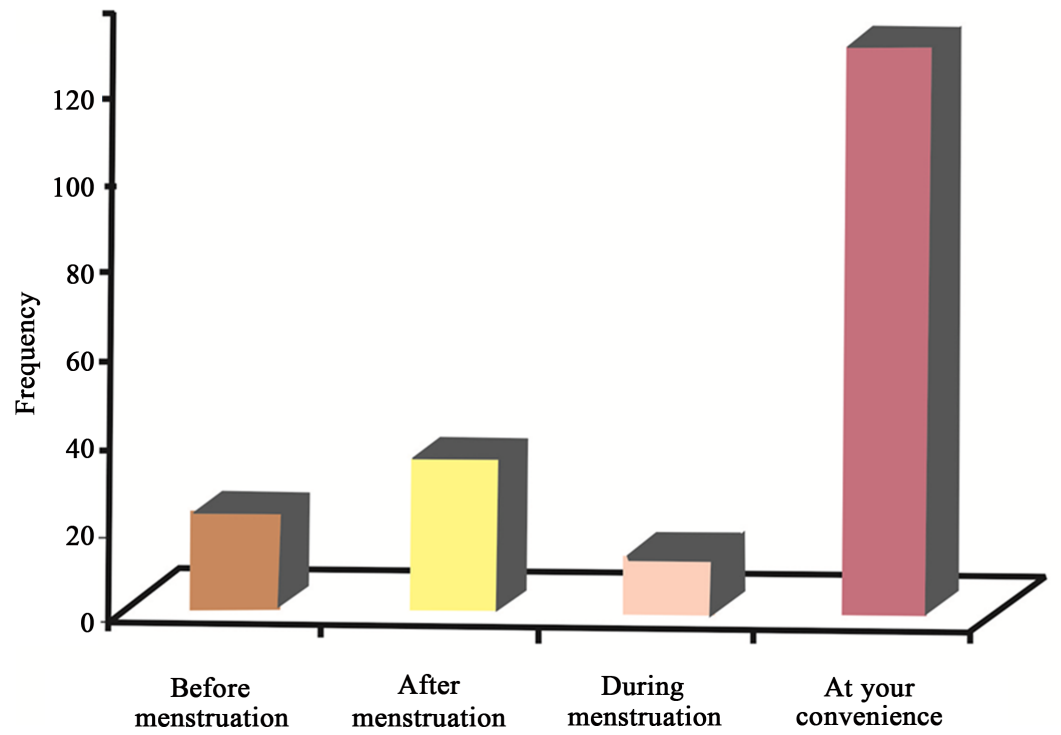

At your convenience

During menstruation

After menstruation

Before menstruation

Figure 1. Time of the month respondents examine their breast.

Table 4. Percentage distribution showing practice of examination of breast.

\begin{tabular}{ccc} 
Response & Frequency & Percentage (\%) \\
\hline Examine breast regularly & 150 & 75.0 \\
Not examining breast regularly & 50 & 25 \\
Total & $\mathbf{2 0 0}$ & $\mathbf{1 0 0}$ \\
\hline
\end{tabular}


Table 5. Do you freely perform SBE.

\begin{tabular}{ccc}
\hline Response & Frequency & Percentage (\%) \\
\hline Yes & 169 & $84.5 \%$ \\
No & 31 & $15.5 \%$ \\
Total & $\mathbf{2 0 0}$ & $\mathbf{1 0 0 \%}$ \\
\hline
\end{tabular}

Table 6. Responses on where respondents carry out self breast examination.

\begin{tabular}{ccc}
\hline Place & Frequency & Percentage (\%) \\
\hline In front of mirror & 102 & 51.0 \\
When taking a shower & 41 & 20.5 \\
Hospital & 26 & 13.0 \\
None & 31 & 15.5 \\
Total & $\mathbf{2 0 0}$ & $\mathbf{1 0 0}$ \\
\hline
\end{tabular}

Table 7. One way analysis of variance for factors affecting SBE practice amongst the university students.

\begin{tabular}{|c|c|c|c|c|c|}
\hline Respondent & $\mathbf{N}$ & & Mean & SD & \\
\hline Forgetfulness & 96 & & 28.53 & 2.14 & \\
\hline Afraid & 80 & & 24.87 & 1.96 & \\
\hline Feel bad & 15 & & 23.11 & 2.43 & \\
\hline Feel irritating & 9 & & 20.32 & 3.12 & \\
\hline Total & 200 & & & & \\
\hline Source of variance & SS & Df & MS & F-value & Sig. \\
\hline Within groups & 21.742 & 3 & 4.348 & 14.656 & 0.000 \\
\hline Between groups & 113.341 & 196 & 0.297 & & \\
\hline Total & 135.082 & 199 & & & \\
\hline
\end{tabular}

As presented in Table 7, one way analysis of variance was used to investigate the factors that affected SBE at 0.05 level of significance, the calculated F-value of 14.656 was greater than the critical F-ratio of 3.00 at 0.05 with 3, 196 degree of freedom. This result implies that forgetfulness, being afraid, bad feeling and feeling irritated affect SBE. Therefore the null hypothesis which states that, there is no significant difference between factors affecting SBE is rejected while the alternate hypothesis is retained. A cursory look at the mean values reveal that forgetfulness as a factor has the highest mean value, meaning that it is a potent factor that affected SBE amongst the subjects studied.

\section{Discussion of Findings}

This study sought to assess the knowledge and practice of BSE amongst students in the Department of Nursing Science, in Benin City. The respondents were aged 17 - 20 years and 21 - 25 years and majority are from Bini, Isoko, Igbo, and Yoruba. Many of the respondents are single, only 11\% were married. Majority of the respondents were Christians. Questionnaire was utilized in the study which was pre-tested and the reliability was found to be good (0.8).

The findings of this study showed majority of the nursing students were knowledgeable about self-breast examination, this is in agreement with Janice and Kerry (2013) who estimated that 85\% - 90\% of students perform self breast examination monthly [13], but in Contrast to the results of Doshi et al. (2012) who noted that the 
practice of BSE among Indian dental students was quite alarmingly low [14].

Majority of the students practice self breast examination and further findings revealed that $11 \%$ of them said they examine their breast before menstruation, $17.5 \%$ after menstruation, $6.5 \%$ during menstruation and $65 \%$ at their conveniences. This showed that, although SBE was practiced, it was not consistent. This supports the findings of Bassey et al. (2011) who revealed that those who had carried out SBE did so to examine their breasts because they have a family history of breast cancer [2]. Doshi et al. (2012) revealed in their study that the practice of BSE amongst a group of Indian dental students was alarmingly low [14].

This study revealed that majority of the respondents did not have negative misconceptions self breast examination. This is in line with the findings of Budden (1995), who explained that student nurses freely talk about self breast examination and others should be encouraged to freely talk on self breast examination [15]. Our study revealed that there is a significant relationship between the factors affecting SBE and forgetfulness is the major factor affecting the practise of SBE amongst the university students.

\section{Conclusion}

Self breast examination (BSE) is a screening method used in an attempt to detect early breast cancer. The method involves the woman herself looking at and feeling each breast for possible lumps, distortions or swelling. It is the quickest way to detect any abnormality in the breast. It's simple, easy and not expensive. Nursing students in the University of Benin are aware of self breast examination and practice it. They are also aware of the time of the month to carry out the procedure and also what to look for when performing self breast examination.

\section{Recommendation}

In the light of this study, self breast examination is a simple, easy and non-expensive procedure, therefore, I recommend that:

* The university management should encourage the students, as a matter of compulsion, to go for breast examination regularly.

* Nursing students who are aware of the importance of SBE should educate their fellow students and also pass the message on to the general public.

* Nursing students should freely report to the hospital when any abnormality is noticed on the breast during its examination.

\section{References}

[1] Agboola, A.O., Deji-Agboola, A.M., Oritogun, K.S., Musa, A.A., Oyebadejo, T.Y. and Ayoade, B.A. (2009) Knowledge, Attitude and Practice of Breast Self Examination in Female Health Workers in Olabisi Onabanjo University Teaching Hospital, Sagamu, Nigeria. International Medical Journal, 8, 5-10.

[2] Bassey, R.B., Irurhe, N.K., Olowoyeye, M.A., Adeyomoye, A.A. and Onajole, A.T. (2011) Knowledge, Attitude and Practice of Breast Self-Examination among Nursing Students in Lagos University Teaching Hospital, Nigeria. Educational Research, 2, 1232-1236.

[3] Iheanacho, P., Ndu, A. and Emenike, A. (2013) Awareness of Breast Cancer Risk Factors and Practice of BSE among Female Undergraduates in University of Nigeria Enugu Campus. Open Journal of Nursing, 3, 147-152. http://dx.doi.org/10.4236/ojn.2013.31019

[4] World Health Organization (2013) Breast Cancer: Prevention and Control. http://www.who.int/cancer/detection/breastcancer/en/print.html

[5] Balogun, M.O. and Owoaje, E.T. (2005) Knowledge and Practice of Breast Self Examination among Female Traders in Ibadan, Nigeria. Annals of Ibadan Postgraduate Medicine, 3, 52-56. http://dx.doi.org/10.4314/aipm.v3i2.39067

[6] Ferlay, J., Shin, H.R., Bray, F., Forman, D., Mathers, C. and Parkin, D.M. (2010) Estimates of Worldwide Burden of Cancer in 2008: GLOBOCAN 2008. International Journal of Cancer, 127, 2893-2917. http://dx.doi.org/10.1002/ijc.25516

[7] Faronbi, J.O. and Abolade, J. (2012) Self Breast Examination practices among Female Secondary School Teachers in a Rural Community in Oyo State, Nigeria. Open Journal of Nursing, 2, 111-115. http://dx.doi.org/10.4236/ojn.2012.22017

[8] Oluwatosin, O. (2012) Primary Healthcare Nurses’ Knowledge, Practice and Clients Teaching of Early Detection Measures of Breast Cancer in Ibadan. BMC Nursing, 11, 1-8. http://dx.doi.org/10.1186/1472-6955-11-22 
[9] Susan, G. (2013) Breast Cancer Risk Factors. www.komen.org/risk

[10] Waston, S. (2002) Breast Self Examination. www.ask.com

[11] Agwu, U.M., Ajaero, E.P., Ezenwelu, C.M., Agbo, C.J. and Ejikeme, B.N. (2007) Breast Self Examination Knowledge, Attitude and Practice of Breast Self Examination among Nurses in Ebonyi State University Teaching Hospital, Abakiliki. European Medical Journal, 6, 44-47.

[12] Alsaif, A.A. (2004) Breast Self-Examination among Saudi Female Nursing Students in Saudi Arabia. Saudi Medical Journal, 11, 1574-1578.

[13] Janice, L. and Kerry, H. (2008) Brunner and Suddarth’s Textbook of Medical-Surgical Nursing. Medical Surgical Nursing. 11th Edition, Williams and Wilkins Lippincolt Publishers, London.

[14] Doshi, D., Srikanth, B., Kulkarni, S. and Karunakar, P. (2012) Breast Self-Examination: Knowledge, Attitude, and Practice among Female Dental Students in Hyderabad City, India. Indian Journal of Palliative Care, 18, 68-73. http://dx.doi.org/10.4103/0973-1075.97476

[15] Budden, L. (1995) Young Women’s Breast Self-Examination Knowledge and Practice. Journal of Community Health Nursing, 12, 23-32. http://dx.doi.org/10.1207/s15327655jchn1201_3 